\section{Frequency of use} of Indian systems of Medicine and homeopathy among
diabetic patients in
Chennai (CURES-80)

Sir, It is believed that a significant number of Indian diabetic patients use Indian System of Medicines and Homeopathy (ISM\&H) to control their blood sugar levels. An earlier study suggested that 'no side effects and low cost of treatment' were the main reasons for people preferring ISM\&H. ${ }^{[1]}$ Other reasons quoted for widespread use of Complementary and Alternative Medicines (CAM) by patients with diabetes mellitus was their expectation of early and maximum benefit. ${ }^{[2]}$ One hospital-based study showed that $67 \%$ of patients were using CAM, including ISM\& $\mathrm{H}^{[3]}$ However, hospital-based studies are subject to referral bias. To our knowledge, there is no population based data on this aspect. The aim of the present study was to assess the use of ISM\&H among diabetic patients in Chennai.

The Chennai Urban Rural Epidemiology Study (CURES) is a large cross-sectional epidemiological survey conducted on 26,001 randomly selected residents representative of Chennai selected from the 10 zones of the corporation of Chennai. ${ }^{[4]}$ After obtaining a signed informed consent, information about the participant's health status, self-reported history of diabetes, types of medication used, including ISM medicines were obtained. Fasting capillary blood glucose was determined using a glucometer and those with fasting blood glucose values $<100 \mathrm{mg} / \mathrm{dL}$ were considered as under control.

Of the 26,001 participants, 182 refused to provide blood samples. A total of 4,758 (18.3\%) participants had diabetes, of whom 1,529 (5.9\%) had "known diabetes" and 3,229 (12.4) had newly detected diabetes. Among the 1,529 "known" diabetic subjects, 954 (62.4\%) were using some form of medication and 438 (28.7\%) had their fasting blood glucose under control.

Among the known diabetic subjects on medications, only 41 (2.7\%) patients were using some form of ISM\&H. The break down of the 41 patients was as follows: [Ayurveda: 20, Homeopathy: 7, Unani: 3, Siddha: 3 and others: 8]. Two patients reported the use of both allopathic as well as ISM\&H medicines, while 3 patients used only ISM\&H medicines. Fasting blood glucose levels were higher in patients using ISM\& $\mathrm{H}$ when compared to those using allopathic medicines [208 $\pm 106 \mathrm{mg} / \mathrm{dL}$ vs. $172 \pm 77 \mathrm{mg} / \mathrm{dL}, P<0.001]$.

This study indicates that among known diabetic patients in Chennai, $2.7 \%$ were utilizing ISM\&H medications for the treatment of diabetes. More studies are needed in other parts of India, particularly in rural areas, where use of ISM\&H for diabetes may be higher.

Thillaigovindan Parivallal, Ranjit Mohan Anjana, Viswanathan Mohan

Department of Diabetology, Madras Diabetes Research Foundation and Dr. Mohan's Diabetes Specialities Centre, WHO Collaborating Centre for Non Communicable Diseases Prevention and Control, International Diabetes Federation Centre of Education, Gopalapuram, Chennai, Tamil Nadu, India

Corresponding Author: Dr. Viswanathan Mohan Dr. Mohan's Diabetes Specialities Centre, WHO Collaborating Centre for Non Communicable Diseases Prevention and Control, International Diabetes Federation Centre of Education, National President, Research Society for the Study of Diabetes In India, No:6B, Conran Smith Road, Gopalapuram, Chennai - 600 086, Tamil Nadu, India. E-mail:drmohans@diabetes.ind.in

\section{REFERENCES}

1. Singh P, Yadav RJ, Pandey A. Utilization of indigenous systems of medicine and homeopathy in India. Indian $\mathrm{J}$ Med Res 2005;122:137-42.

2. Kumar D, Bajaj S, Mehrotra R. Knowledge, attitude and practice of complementary and alternative medicines for diabetes. Public Health 2006;120:705-11.

3. Mehrotra R, Bajaj S, Kumar D. Use of complementary and alternative medicine by patients with diabetes mellitus. Natl Med J India 2004;17:243-5.

4. Deepa M, Pradeepa R, Rema M, Mohan A, Deepa R, Shanthirani S, et al. The Chennai Urban Rural Epidemiology Study (CURES) study design and methodology (Urban Component) (CURES - 1). J Assoc Physicians India 2003;51:863-70.

\begin{tabular}{|l|l|}
\hline \multicolumn{2}{|c|}{ Access this article online } \\
\hline Quick Response Code: & Website: \\
\hline & www.josh.net \\
\hline & \\
\hline
\end{tabular}

